\title{
Rua do Ouvidor, itinerário de Memórias
}

\author{
Ubiratan Machado Pinto*
}

\begin{abstract}
Resumo: Para oferecer aos leitores de seu tempo o testemunho de dados históricos acerca da Rua do Ouvidor, o Dr. Joaquim Manuel de Macedo apresenta "crônicas de costumes" que refletem as transformações urbanas dessa rua na cidade do Rio de Janeiro. Dessa forma, o texto restabelece itinerários que remetem desde ao passado colonial do Novo Mundo até ao século XIX, sendo fundamental, portanto, contemporizar diacronicamente as circunstâncias pelas quais a notória rua, por intermédio da memória, é observada como parte do processo civilizatório engendrado sob influência do Velho Mundo.
\end{abstract}

\begin{abstract}
To offer his readers a testimony of historical data about the Ouvidor Street, Dr. Joaquim Manuel de Macedo presents customs chronicles which reflect the urban transformations through which this street in Rio de Janeiro went. In this way, the text reestablishes itineraries that date back from our colonial past to the XIX century. Thus, it is fundamental to diachronically establish the circumstances through which the famous street, through the memory, is observed as a part of the civilization process articulated under the influence of the "Old World".
\end{abstract}

Keywords: imaginary; street; memory.

Ao publicar Memórias da Rua do Ouvidor, originalmente sob forma de folhetins semanais no Jornal do Comércio, Joaquim Manuel de Macedo delimita-se à recuperação de fatos históricos para definir o percurso diacrônico de uma das mais notórias ruas da cidade do Rio de Janeiro. Como modo de preservar as procedências de todas as transformações porque passam os contornos antes primitivos dessa cidade e reinstaurar tempos pretéritos, o escritor estabelece, através da memória, razões que repousam no passado colonial das nossas terras brasileiras e numa temporalidade mais recente da época moderna, resgatando peculiaridades e registros dos arquivos públicos, conforme a compilação das crônicas reunidas nessa obra, divulgadas em 1878. Tal proposta abarca, portanto, as referidas circunstâncias sem permitir que essas fiquem engessadas numa anacronicidade inconveniente com a demanda de leitura que se espera (amores folhetinescos, platônicos, impossíveis; casualidades e ocorrências surpreendentes ou imprevisíveis), uma vez que o recurso de ficcionalizar eventos verídicos aproxima os leitores do século XIX de acontecimentos que permearam a história dessa rua e

\footnotetext{
* Graduando e Bolsista
} 
as denominações pelas quais foi designada até chegar a ser conhecida como tal, a Rua do Ouvidor:

A Rua do Ouvidor, a mais passeada e concorrida, e mais leviana, indiscreta, bisbilhoteira, esbanjadora, fútil, noveleira, poliglota e enciclopédica de todas as ruas da cidade do Rio de Janeiro, fala, ocupa-se de tudo; até hoje, porém ainda não referiu a quem quer que fosse a sua própria história. (MACEDO, 2005, p. 9)

E a cidade do Rio de Janeiro foi fundada por Mém de Sá em 1567 sobre o monte São Januário. Assim, as primeiras denominações que essa rua tivera fora "Desvio do Mar", "Rua de Aleixo Manuel", todas mencionadas e justificadas por Macedo (2005, p. 12), o memorista "que se reserva direitos confessos de imaginação" ao se debruçar em "velhos manuscritos ricos de tradições que expliquem o que se ignora". Com referência a mais de duzentos anos adensados por suas reflexões sempre partilhadas com seu interlocutor, as lembranças que o autor constrói reforçam a distinção da Rua do Ouvidor no imaginário coletivo e mimetiza a realidade para escapar de qualquer equívoco a fazê-lo sucumbir a análises retrógradas. "Em memórias históricas o anacronismo é naufrágio, e eu estava deveras naufragando em anacronismo" (MACEDO, 2005, p. 32). Ciente de que sua função requer responsabilidade para com informações tão relegadas à erosão do tempo, ele se permite imaginar, configurar ocorrências em descompasso com seu tempo.

Quando imagino episódios para suavizar a leitura destas Memórias, indico-os sempre com bastante clareza: Agora não imagino, não invento a tradição, mas refiro-a, porque se não é verdadeira é bem achada. (MACEDO, 2005, p. 33)

Com esse intuito, Joaquim Manuel de Macedo fornece aos leitores o perfil da Rua do Ouvidor, o "belo sexo" que bem considerou de qualificá-la, concedendo uma identidade física, redobrando a fama dessa rua, além de recuperar designações antigas como se estivesse reconstituindo todas as curvas e grafias obscurecidas pela reutilização de um mesmo palimpsesto:

Mas enfim a rua de Aleixo Manuel passou a chamar-se do padre Homem da Costa, nome que conservou por cento e vinte anos, tendo trocado a casaca e a cabeleira do cirurgião pela batina e pelo solidéu do padre, e faz vontade de rir imaginar beata e clerical durante um século e anos esta rua do Ouvidor filósofa sensualista, e até rua um pouco ou muito endemoninhada pela multiplicação das tentações. (MACEDO, 2005, p. 35)

De acordo com José Luís Romero, a dura tarefa do homem que se empenha por indagar a verdade acerca do passado difere dos trabalhos que exigem outras maneiras de conhecimento porque não está tão somente pelo desejo de descobrir certo aspecto da realidade $^{1}$ (cf. ROMERO, 1988, p. 64). Em razão de estar sob influência da monarquia

\footnotetext{
${ }^{1}$ Versão original: "La dura tarea del hombre que se afana por indagar la verdad acerca del pasado se distingue de las labores que exigen otras maneras del conocimiento porque no está movida tan sólo por el deseo de descubrir cierto aspecto de la realidad".
} 
portuguesa, a imigração de contingente humano na cidade do Rio de Janeiro, colaborando para a expansão comercial e a habitação do território colonial, propicia gradualmente a necessidade de urbanizar a paisagem carioca, de erradicar índices de insalubridade em que se expusera em meados do século XVIII.

Em 1764 ou 1765 o Vice-Rei Conde da Cunha ordenou à Câmara Municipal da cidade que fizesse cobrir com lajes grossas a Vala fétida e pestífera; a obra executou-se prontamente, e para que não fosse todo prejudicado o esgoto das águas das chuvas, a Vala recebeu ralos de pedra no encruzamento das ruas. (MACEDO, 2005 p. 36)

Desse modo, a resolução do saneamento e a definição da estrutura da via por onde os transeuntes de outrora puderam caminhar colaboram, no entanto, para a formação da cidade, como observa Pesavento (2006, p. 209): "produto do social, afirmação de uma humanidade que busca dominar a natureza, que se tem uma modificação da paisagem, dada não somente pela transformação do espaço e do meio como pela diversificação e proliferação das relações sociais". Essas são as justificativas enraizadas no cerne da engrenagem que impulsiona a Rua do Ouvidor para o seu próprio devir. Cabe ao leitor, então perfazer com Macedo o itinerário da "filósofa sensualista":

De 1770 a 1791 a cidade de S. Sebastião do Rio de Janeiro se transformou como metamorfose rápida. Era feia lagarta, e o Vice-Rei Marquês de Lavradio fez sair do casulo a borboleta, asseando, calçando as ruas e praças, abrindo novas ruas, banindo as rudes peneiras das portas e janelas, e removendo para longe dos centros urbanos a aglomeração pestífera dos míseros negros trazidos da África para imundos recintos de mercado de escravos. (MACEDO, 2005, p. 53)

Isso é o que poderíamos significar como o despertar da consciência histórica que resgata a compreensão do passado, indagando quais as circunstâncias ocorridas e sob que imperativos se produziu esse conhecimento ${ }^{2}$ (cf. ROMERO, 1988, p. 66). Como não pode referir-se a história dessa rua sem deixar de recuperar também o contexto histórico ao redor, o escritor marca aspectos e peculiaridades dela, a origem, enfim, do motivo de ser chamada como é conhecida até hoje:

Um ouvidor de comarca era naquele tempo muito mais do que um simples mortal, era um potestade, que o povo respeitava mais do que hoje respeita ao presidente do Supremo Tribunal de Justiça, e não havia quem deixasse de pôr-se de chapéu na mão quando ele passava.

Desde que Dr. Berquó estabeleceu sua residência à rua do padre Homem da Costa, desfizeramse as pretensões denominativas de Rua do Amotinado e do Cabido, e todos de acordo a chamaram rua do Ouvidor. (MACEDO, 2005, p. 59)

Por isso, episódios de situações curiosas não faltam para serem narrados a um aventurado leitor, fatos como a "tradição-romance" do caso amoroso entre Perpétua Mineira e

\footnotetext{
${ }^{2}$ Citação no idioma original: “[...] el despertar de la conciencia histórica acusa a un tiempo mismo los signos de la crisis de una comunidad y los rumbos hacia los que se dirige; nada tan fecundo para llegar a sorprender la viva llama que anima el conocimiento del pasado como indagar en qué circunstancias ocurre y bajo qué imperativos se produce".
} 
o inconfidente Tiradentes, e o "episódio da maçã̃" cuja fruta, advinda da Rua do Ouvidor, pela irmã teria sido enviada ao cárcere de outro inconfidente, visto que, no interior dessa fruta, havia uma mensagem confidencial. Finalmente, podemos entender porque “[...] a rua começou a denominar-se do Ouvidor em 1780" (MACEDO, 2005, p. 60). E a rua submete-se, do século XVIII em diante, às inovações arquitetônicas.

As rótulas e gelosias não eram cadeias confessas, positivas, mas eram pelo aspecto e pelo seu destino grandes gaiolas, onde os pais e maridos zelavam sonegadas à sociedade as filhas e as esposas.

A higiene, a arquitetura, o embelezamento da cidade exigiam a destruição das malignas e feias gaiolas.

E a rua do Ouvidor devia ser pronta, como foi, em dar cumprimento ao edital de Paulo Fernandes, porque rótulas e gelosias destinadas a esconder à força o belo sexo deviam ser imediatamente banidas da rua que não tarde tinha de tornar-se por excelência de exposição diária de elegantes e honestíssimas senhoras, e infelizmente também andorinhas que por ali fazem verão. (MACEDO, 2005, p. 91)

Desmoronava a cidade da submissão perante os olhos mercantis da Europa e edificava-se uma cidade em progresso, rumo às benesses da política liberal. A rua do século XIX é predestinada, em conformidade com os argumentos de Pesavento (2005, p. 210) "ao espaço do negócio, da festa, da novidade, de uma outra forma de relacionamento social”. E Macedo faz suas referências com relação a esses fatos.

No Rio de Janeiro, a rua do Ouvidor foi uma das primeiras a ter casas ou estabelecimentos de negociantes ingleses, lojas de louça, de fazendas ou panos tecidos, e enfim de comércio de importação e de exportação de gêneros recebidos da Inglaterra e mandados do Brasil, e portanto antes de ouvir dizer monsieur e sacre nom de Dieu ouviu repetir mister e goodemi e comeu batatas inglesas antes de comer petit pois. (MACEDO, 2005, p.92)

França e Inglaterra eram países politicamente antagônicos entre si em função do Bloqueio Continental, que decretava a proibição das práticas de comércio sob território do império napoleônico aos ingleses (o governo português abandona Portugal, pois se recusa a aceitar o bloqueio para não perder a colônia brasileira e por estabelecer relação financeira com os ingleses). Todavia, após o acordo de paz no Congresso de Viena, em 1815, devido ao fim do império de Napoleão Bonaparte, e à abertura dos portos brasileiros para o livre comércio, esses países trazem ao Brasil suas contribuições culturais através da confluência de idiomas, introduzem um modo europeizado de circular pelas ruas e de viver em sociedade civilizada e representam as promissoras influências à construção do espaço urbano, principalmente as "francesas":

Não foi de franceses, foi de francesas a colônia artística que chegou ao Rio de Janeiro a 26 de março de 1816 , e não era a palheta do pintor, nem o buril do estatuário, era somente a tesoura das modistas que havia de levantar o monumento da rua do Ouvidor. (MACEDO, 2005, p. 97)

Evidente que os "costumes do tempo" estabelecem novas formas de relacionamento no meio social incorporadas ao modo de ser por intermédio de mentalidade que legitima o 
status quo da elite burguesa européia no submundo da América Latina, "porque a cidade era vista como o ativo, a civilização, o fermento operativo, apta precisamente para difundir as formas de vida e as idéias que a burguesia elaborava" (ROMERO, 1987, p. 20). Condicionada a essa lógica, a Rua do Ouvidor apresenta-se ao mundo conforme a ambição da classe elitista, voltada para os trâmites comerciais e industriais.

De súbito, e como de plano, mas sem que o tivessem consertado, pronunciou-se, de 1821 a 1822, a hégira das modistas francesas para a Rua do Ouvidor. [...] E após as modistas, à sombra das francesas vieram quase logo franceses abrir, na mesma Rua do Ouvidor, lojas e fazendas e de objetos de modas, para senhoras e homens, de perfumarias, de cabeleireiros, etc. (MACEDO, 2005, p. 100-101)

Era preciso modernizar a cidade. Com isso, havia de passar a cidade do Rio de Janeiro por um processo de urbanização inevitável que concordaria com a concepção da classe que se predispunha a aprimorar sua rústica vida em terras estrangeiras por intermédio de sua própria concepção de mundo, o mundo civilizado, polido, mercantilista.

En rigor, todo el mundo urbano puede ser visto como una creación, o mejor una invención: como forma física, como estructura social, como concepción de la vida. Todo lo que ocurre en la ciudad está montado sobre un principio de sofisticación, antinatural: desde el pavimento de las calles, la posibilidad de encerrarse entre cuarto paredes o, más en general, la voluntad de un grupo de vivir de una cierta manera dentro de ese recinto por él creado. Pero lo específico de la invención burguesa no es la ciudad física, similar a la ciudad antigua, sino el tipo de pensamiento que informa la creación y que, luego, se crea en la ciudad ${ }^{3}$. (ROMERO, 1987, p. 21-22)

Acompanhando esse raciocínio, eis as nuanças de modernidade que a ditosa rua começa a exibir no panorama da mise en scène carioca:

Rompera, enfim, a época da real e crescente celebridade rua do Ouvidor pela dominação da Moda de Paris, essa rainha despótica que governa e floresce decretando, modificando, reformando e mudando suas leis em cada estação do ano, e sublimando seu governo pelo encanto da novidade, pela graça do capricho, pelas surpresas da inconstância, pelo delírio da extravagância, e até pelo absurdo, quando traz para o rígido verão do nosso Brasil as modas do inverno de Paris. (MACEDO, 2005, p. 106)

Portanto, "a rainha Moda de Paris firmou seu trono na rua do Ouvidor", a "França Antártica”, como se deixa ser designada, "desde a Primeiro de Março até a Praça de S. Francisco de Paula” (MACEDO, 2005, p.107-108). Dessa forma, o escritor conduz uma "viagem do princípio ao fim da mesma rua como propósito de considerar e lembrar seus edifícios notáveis e suas casas dignas de distinção por interessantes recordações”, onde circulam "bondes e carros, carrinhos e carroças" (MACEDO, 2005, p.110-112), onde se

\footnotetext{
${ }^{3}$ Tradução: Em rigor, todo o mundo urbano pode ser visto como uma criação, ou melhor, uma invenção: como forma física, como estrutura social, como concepção da vida. Tudo o que ocorre na cidade está montado sobre um princípio de sofisticação, antinatural: desde o pavimento das ruas, a possibilidade de encerrar-se entre quatro paredes ou, geralmente, a vontade de um grupo de viver de uma certa maneira dentro desse recinto por ele criado. Mas o específico da invenção burguesa não é a cidade física, similar a cidade antiga, senão o tipo de pensamento que informa a criação e que, logo, se cria na cidade.
} 
saciavam da vida urbana literatos, políticos, ingleses, franceses, gente de toda a parte, contingente cosmopolita como era (e continua sendo) a da cidade carioca, também reduto de Chalaça, amigo particular de D. Pedro I. Rua predestinada às paixões humanas, suscetível às peripécias do cotidiano e da imaginação do amor de folhetim, do amar de longe, à espreita da censura moral da sociedade. Sempre os "costumes do tempo", ao que se remete Macedo (2005, p, 135-136), de pente e penteados de "trepa-moleques", cabelos "à romântica", repartição de cabelo "estrada da liberdade", a moda francesa, as transformações políticas, a imprensa, a gazeta diária, o fervor de uma rua em turbilhão. O problema da falta de saneamento e os "barris asquerosos" denominados "tigres", "pelo medo explicável com que todos fugiam dele" (MACEDO, 2005, p.139), em contraste com o requinte de perfumes e as lojas de perfumaria, as modistas, a "Mlle Joséphine", "a modista da primeira imperatriz do Brasil [...]" (MACEDO, 2005, p.148). Macedo vai nos guiando por essa rua, indica números de placas das casa, adentra nas que resguarda(va)m histórias, episódios tão-somente vivenciados na rua daquele Dr. Berquó, a rua do Ouvidor: "pouco adiante da casa n. ${ }^{\circ} 89$ temos que demorar-nos de novo, considerando a de n. ${ }^{\circ} 95$, placa, que é atualmente Depósito de Máquinas Americanas de Costura" (MACEDO, 2005, p.149). E segue: “[...] à casa n. 95 a de 97, à de Mme Finot a florista, a casa onde explorou boa mina de ouro, vendendo frutas, $M$. Vannet, um dos mais antigos franceses da rua do Ouvidor". E ainda: "aquela casa n. ${ }^{\circ} 113$ [...] foi levantada no lugar onde se mostrava a antiga e pequena casa térrea de duas portas, que ainda em 1838 era loja de livros do Albino Jordão" (MACEDO, 2005, p.152-153). Muitos fatos e personagens dentre os quais alguns certamente imaginados, e outros que realmente existiram, o "Teatro Lírico Francês", as "linhas de bondes de Botafogo e das Laranjeiras" com ponto de partida e chegada "na rua de Gonçalves Dias quina da do Ouvidor" (MACEDO, 2005, p.156). E o escritor nos avisa:

O melhor é que os meus companheiros de viagem façam de conta que lhes conto um romance, procurando diverti-los.

Seja um romance da rua do Ouvidor criado pela minha imaginação, e por isso mesmo lá vai com tal qual forma de romance. (MACEDO, 2005, p.158)

E, bem ao final de Memórias..., a contabilização do preço que paga a nossa Rua do Ouvidor:

Calculem a despesa do estabelecimento que aliás floresce e se agiganta!... que soma de contos de réis gastos anualmente com essa população!...

Calculem o que ganham em seu comércio as muitas outras embora menos gigantescas lojas de modas da rua do Ouvidor, e hoje de outras ruas.

Calculem e façam idéia do que custam a moda e a elegância da cidade do Rio de janeiro!...

Porque em cada corte de seda, em cada toalete, em cada xale, chapéu, gravatinha, etc., a compradora paga e deve pagar no seu tanto proporcional, além do valor e lucro do objeto que adquire, o aluguel da casa, e os honorários dos empregados de escritório, dos caixeiros, das 
modistas, das costureiras, dos serventes e dos criados, e antes de tudo isso os tributos da alfândega, que na verdade são de arrasar!... (MACEDO, 2005, p.184)

Não é possível enumerarmos as intermináveis lojas, os vultos notáveis e os casos pertinentes a essa rua. "A Ouvidor era o próprio Brasil culto e civilizado, dotado, como as crenças e religiões, do poder mágico de uma verdade revelada. Era preciso sentir, acreditar e entendê-la como um centro nervoso da vida nacional [...]” (PESAVENTO, 1999, p. 189-190). Assim, Memórias... debruça a rua em seu próprio reflexo, reproduz a "imagem do espelho para traduzir a força do imaginário em recriar o real, reatualizando sentidos e imprimindo novos significados", para que os leitores se deleitem, "tornando as representações mais “concretas" e "desejáveis" do que a própria realidade" (cf. PESAVENTO, 1999, p. 210). Temos impressão, enfim, de que Macedo procura justificativas que correspondam à identidade do país através da rua na qual desembocam todas as verdades e inverdades da História do Brasil, todos os mitos e crenças nascidas da miscigenação e das revoltas e rebuliços de ordem política. Afinal de contas, resgata-se, como diz Pesavento (1999, p.210), "um padrão de referência identitária nacional, num viés metonímico que permite a sensação da modernidade introjetar-se no país, através da representação metropolizada do Rio", subordinada, entretanto, ao que a Rua do Ouvidor absorvera toda para si, elaboração metropolizada em si mesma no interior da própria metrópole, entidade arquetípica que simboliza essa sensação da modernidade, isto é, do mundo que cabe dentro de uma rua.

\section{Referências}

MACEDO, Joaquim Manuel de. Memórias da Rua do Ouvidor. Brasília: Senado Federal, Conselho Editorial, 2005.

PESAVENTO, Sandra Jatahy. O imaginário da cidade: visões literárias do urbano - Paris, Rio de Janeiro, Porto Alegre. Porto Alegre: Editora da Universidade/UFRGS, 1999.

A Paisagem social como imaginário de sentido. In: DIMAS, Antonio; LEENHARDT, Jacques; PESAVENTO, Sandra Jatahy (orgs). Reinventar o Brasil Gilberto Freyre entre história e ficção. Porto Alegre: Editora da UFRGS/ Editora da USP, 2006.

ROMERO, José Luis. Estudio de la Mentalidad Burguesa. México: Alianza Editorial, S.A., 1987.

. La Vida Historica. Buenos Aires: Editorial Sudamericana, 1988. 